\title{
STIMULATING THE USE OF OMT IN PRIMARY CARE OFFICES VIA POINT-OF-CARE REMINDERS
}

\author{
Annabel Agcopra, DO'; Philip Collins, DO2; Stuti Jha, PhD³; Alison Mancuso, DO, FACOFP²; \\ Danielle Cooley, DO, FACOFP²
}

${ }^{1}$ Riverside Medical Group, Rutherford, NJ

${ }^{2}$ Rowan University SOM, Stratford, NJ

3 Rowan University, Glassboro, NJ

\begin{abstract}
KEYWORDS:
Osteopathic Manipulative Medicine

OMT

Osteopathic Manipulative Treatment

Point of Care

ABSTRACT: Primary care physicians, especially in family medicine, are more prone to use osteopathic manipulative treatment (OMT) than other specialists; however, barriers to OMT use exist. The purpose of this study is to evaluate if the frequency of OMT use in a family medicine outpatient setting is influenced by having posters promoting OMT in exam rooms and waiting rooms.

Methods: OMT posters were placed in two of four offices in an academic family medicine practice. Offices without posters served as the control group. Billing patterns were examined for the five months prior to and after poster placement. Report parameters included: age, gender, ethnicity, CPT code for OMT and somatic dysfunction ICD-10 codes.

Results: Data before and after poster placement were compared. Results showed a positive correlation between posters advertising OMT and OMT use. There was a $6.5 \%$ increase in OMT use in the offices that had posters advertising OMT.

Conclusion: This research showed that placing OMT posters in select family medicine offices resulted in an increase in OMT use. Possibilities for this increase include patients becoming more aware of the benefits of OMT and/or simply reminding osteopathic physicians of the benefits of OMT. Increased OMT utilization could lead to a decrease in pain medication prescribing and an increase in functionality through conservative measures.
\end{abstract}

\section{INTRODUCTION}

The principles and practice of osteopathic medicine encompass a profession centered on holistic patient care. One of the most distinguishing differences between osteopathic physicians and their allopathic counterparts is the use of OMT, which is employed to treat an array of medical conditions. ${ }^{1}$ A.T. Still founded the osteopathic medical profession in $1892^{2}$ and at the outset, manual medicine was greatly emphasized. ${ }^{3}$ However, since as early as the 1950s, there has been a steady decline in the use of OMT. Around the 1970s, there was a shift in the field where osteopaths became more specialized and "manipulative treatment [was] de-emphasized and [became] nonexistent."3 One explanation for this downward trend could be an increasing number of osteopathic students who train in allopathic institutions as well as the recent

\section{CORRESPONDENCE:}

Philip Collins, DO I collinsp@rowan.edu

Copyright $\odot 2020$ by the American College of Osteopathic Family Physicians. All rights reserved. Print ISSN: 1877-573X

DOI: $10.33181 / 12061$ transition to a single accreditation system of post-graduate training, where programs are now accredited by the Accreditation Council on Graduate Medical Education (ACGME) instead of the American Osteopathic Association (AOA). ${ }^{4}$ Additionally, it has been shown that interest and training in OMT steadily declines through formal training. ${ }^{5}$ Possible reasons for this include time restraints, other professional interests, poor reimbursements, unsuitable facilities, lack of a philosophic environment and patients' lack of interest in OMT, amongst other explanations. ${ }^{2}$ Additionally, it has been shown that osteopathic physicians perform OMT less as their career progresses. ${ }^{6}$ These findings are concerning because they illustrate a decline in the use of OMT and in the status of osteopathic medicine as a field distinct from its allopathic counterpart. While most osteopathic physicians feel there are philosophic differences between osteopathic and allopathic medicine, they also feel that OMT is a distinguishing feature. ${ }^{4}$

OMT is a safe and effective treatment for various conditions, can be used at any age, and serves as a potential alternative to pain medications. ${ }^{7,89}$ OMT has been shown to help treat many musculoskeletal issues, including chronic low back pain and neck pain, and can lead to improvement of pain and function. ${ }^{10}$ One of the most common reasons for patients to visit their physician 
is low back pain, which is also a leading cause of disability. ${ }^{11,12}$ As OMT has been shown to be an effective treatment for chronic low back pain and is recommended by the American College of Physicians, implementing this treatment modality can be beneficial to patients. ${ }^{8,13}$ Applying effective nonpharmacologic treatments to chronic pain is especially important in light of the increasing number of people experiencing chronic pain and the opioid epidemic our nation is currently facing. $14,15,16$

Finding ways to increase OMT implementation can be challenging. However, previous studies have shown that point-of-care health promotion and treatment reminders in the exam room can influence physicians. ${ }^{17}$ Additionally, it has been shown that patients appreciate health information materials in the office, such as leaflets and posters. ${ }^{18}$ Our study set out to explore whether pointof-care posters that promote OMT increase the frequency with which OMT is performed.

\section{METHODS}

Posters promoting and briefly describing OMT were placed in two of four family medicine offices in a large academic family medicine practice, with the offices without posters essentially serving as a "control." The posters were created by the researchers and included a photo of OMT being performed with a brief description of OMT and a list of common diagnoses that can benefit from OMT (Figure 1). Of the four practice locations, two of the offices staff family medicine residents as well as attending physicians. The other two offices were staffed with attending physicians only. When selecting the offices in which to place the posters, one office with residents was chosen and one office with attending physicians only was chosen to minimize differences between the two groups. All four offices were located in a suburban area and were staffed with osteopathic family physicians. Physicians in these offices were not made aware of the presence of the posters, nor was the project brought to their attention. To track the use of OMT throughout the offices, an automated report examining billing patterns for the five months prior to and the five months during poster placement was obtained. Report parameters included the following: age, gender, ethnicity, CPT code for OMT and somatic dysfunction ICD-10 codes.

\section{Regression Model}

We have used a two-period probit regression model to estimate the effect of posters on the number of patients choosing OMT. The regression model is given below:

$Y_{i t}=\beta_{0}+\beta_{1}$ Intervention $+\beta_{2} X_{i t}+\mu_{i t}$

The dependent variable $Y_{i t}$ is a binary variable that takes the value 1 if it is a patient from the experiment group and 0 if the patient is treated with OMT in the control group during time period $t$. The subscript $i$ denotes the clinical group to which the patient belongs; experiment or control. Running the probit regression gives us the probability of a patient receiving OMT in the experiment group clinics compared to one of the control group clinics. The variable Intervention is another binary variable that takes the value 1 if the patient is treated with OMT during the experiment phase and it takes the value 0 for OMT in the pre-experiment phase. $X^{i t}$ is the set of demographic variables like the patient's age, gender, race,

\section{FIGURE 1:}

\section{Point-of-care OMT poster}

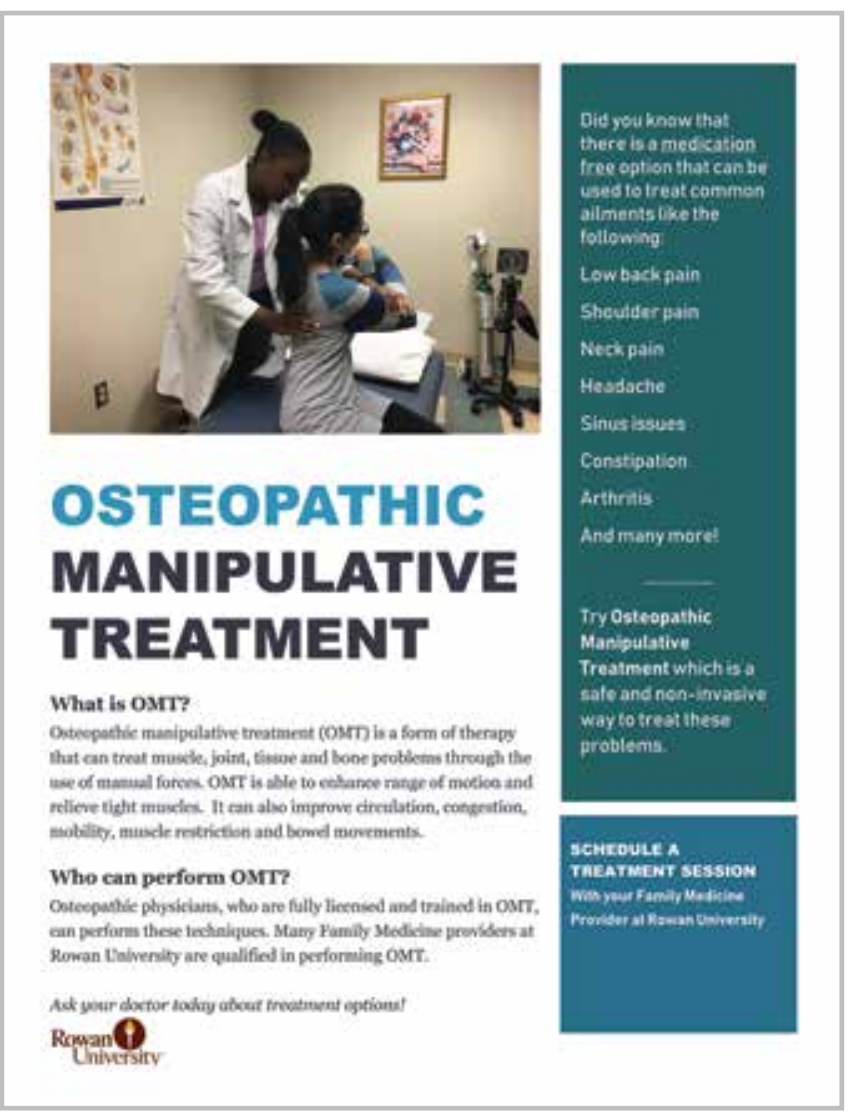

etc. For our analysis, $\beta_{1}$ is the main coefficient of interest as it captures the change in probability of a patient receiving OMT in the experiment group clinics during the experiment phase. A positive coefficient indicates that patients are more likely to be treated with OMT in the two clinics in the experiment group as compared to the control group clinics during the time period the posters were displayed.

\section{RESULTS}

Data before and after poster placement were compared and probit regression analysis was performed. Before poster placement, 9,171 patients were seen in the control group offices (offices without posters), with 88 patients having been treated with OMT. In comparison, 9,381 patients were seen in the experimental group offices (offices with posters), with 335 patients having been treated with OMT. In the period during poster placement, 7,682 patients were seen in the control group offices, with 58 patients having been treated with OMT, while 8,384 patients were seen in the experimental group offices with 374 patients having been treated with OMT. Table 1 summarizes the demographics of the patients treated with OMT in all offices during the timeframe of the study as well as the patient population of the practice. A majority of patients who received OMT in both groups were Caucasian females with an average age of 48 to 49 years old. Race, gender and age range of patients were comparable in both groups. 


\section{TABLE 1:}

Descriptive statistics (mean values) of the patients treated with OMT in all offices during the timeframe of the study as well as the patient population of the practice.

\begin{tabular}{|l|l|l|l|l|}
\hline & $\begin{array}{l}\text { TOTAL } \\
\text { PATIENT } \\
\text { POPULATION }\end{array}$ & $\begin{array}{l}\text { OMT } \\
\text { PATIENTS }\end{array}$ & EXPERIMENT PHASE & $\begin{array}{l}\text { PRE- } \\
\text { EXPERIMENT PHASE }\end{array}$ \\
\hline Observations & 34,618 & 855 & 432 & 423 \\
\hline Female & $63.7 \%$ & $74.2 \%$ & $73.3 \%$ & $75.4 \%$ \\
\hline Male & $36.3 \%$ & $25.7 \%$ & $26.6 \%$ & $25.1 \%$ \\
\hline Asian & $2.1 \%$ & $1.9 \%$ & $1.9 \%$ & $1.9 \%$ \\
\hline Black/African American & $20.1 \%$ & $10.1 \%$ & $0 \%$ & $12.7 \%$ \\
\hline $\begin{array}{l}\text { Native American/Alaskan } \\
\text { Native }\end{array}$ & $0.2 \%$ & $0.2 \%$ & $0.5 \%$ \\
\hline $\begin{array}{l}\text { Native Hawaiian/Pacific } \\
\text { Islander }\end{array}$ & $0.2 \%$ & $0.1 \%$ & $0.2 \%$ & $0 \%$ \\
\hline Other & $1.9 \%$ & $1.4 \%$ & $3 \%$ & $78.4 \%$ \\
\hline White & $65.1 \%$ & $76.6 \%$ & 48.9 & $2.6 \%$ \\
\hline Age (years) & 58.18 & 48.79 & $74.5 \%$ \\
\hline
\end{tabular}

The data shows a positive correlation for those receiving OMT who were exposed to the posters, as compared to those who were not exposed such that there was an increase in OMT performed in the offices with posters advertising OMT during the intervention period. Table 2 shows the probit regression analysis for the intervention period.

\section{TABLE 2:}

Probit regression analysis for the intervention period

\begin{tabular}{|l|l|l|}
\hline VARIABLES & $\begin{array}{l}\text { PROBIT } \\
\text { REGRESSION (1) }\end{array}$ & $\begin{array}{l}\text { MARGINAL } \\
\text { EFFECTS (2) }\end{array}$ \\
\hline Intervention period & $0.267^{* *}$ & $0.0653^{* *}$ \\
\hline & $(0.104)$ & $(0.025)$ \\
\hline Gender & $-0.311^{* *}$ & $-0.070^{* *}$ \\
\hline & $(0.127)$ & $(0.026)$ \\
\hline White & $-0.446^{* *}$ & $-0.096^{* *}$ \\
\hline & $(0.183)$ & $(0.034)$ \\
\hline Black & $-0.689^{* * *}$ & $-0.210^{* * *}$ \\
\hline & $(0.227)$ & $(0.080)$ \\
\hline Age & -0.00173 & -.0004 \\
\hline & $(0.00364)$ & $(0.00089)$ \\
\hline Constant & $1.581^{* * *}$ & \\
\hline & $(0.269)$ & \\
\hline Observations & 854 & 854 \\
\hline
\end{tabular}

Robust standard errors in parentheses

${ }^{* * *} p<0.01,{ }^{* *} p<0.05,{ }^{*} p<0.1$

Control group: patients seen in office without posters advertising OMT Experiment group: patients seen in offices with posters advertising OMT Intervention: Posters placed in the offices designated in the experimental group
Column 2 of Table 2 gives us the marginal effects of a probit regression that analyzes the effect of the intervention on the experimental group. Interestingly, we see that the probability of patients seeking OMT treatment in the experimental group increased by $6.5 \%$ during the intervention period. There are several interesting demographic results, as well. We see that the two major racial groups, White and Black, are less likely to use OMT techniques compared to patients from other racial categories such as Asians and Native Americans in the experimental group. Age doesn't seem to have an impact on the number of patients seeking OMT treatment.

The data would indicate that point-of-care posters can potentially increase the use of OMT in the primary care office setting.

\section{DISCUSSION}

As illustrated by this study, OMT utilization can potentially increase with the implementation of point-of-care reminders. While there are various perceived barriers to OMT from some physicians' perspectives, a simple poster in the exam room may lead to the introduction of OMT into the care of some patients. ${ }^{6}$

It should be noted this study did not delineate how many of the patients' visits were follow-up OMT visits, as opposed to initial visits. Although the impact of the posters may have been overestimated due to this deficiency in delineation, the actual number of OMT procedures may have also been underestimated due to the fact that there could have been some variability in OMT billing practices, especially with residents in the offices. Another limitation of this study is the baseline difference in the number of OMT procedures performed between the two groups. While the total number of 
patient encounters was similar, there was a contrast between the number of OMT procedures performed at baseline, which would indicate fewer physicians performing OMT at those control group offices.

Moving forward, studies should explore whether the utilization of OMT differs at various stages of medical training as it would be interesting to investigate whether there are differences in OMT usage among residents and attending physicians. Finally, continued exploration of point-of-care reminders and further examination of their impact both for patients and osteopathic physicians would be both interesting and helpful to improve practice and patient care.

\section{CONCLUSION}

This research shows that placing OMT posters in select family medicine offices resulted in an increase in OMT use. This observed increase may be explained by the patient's increased awareness of the benefits of OMT and/or the posters simply reminding osteopathic physicians of the benefits of OMT. Whatever the cause, the outcome of increased OMT usage has the potential to improve patient care in osteopathic practice. Moreover, these findings may be particularly useful in combating the current health emergency we are experiencing in the opioid crisis. Studies have shown that a comprehensive approach to chronic pain treatment should be taken, including nonpharmacologic modalities. ${ }^{14}$ Expanded use and awareness of OMT has the potential to decrease pain medication prescriptions and increase functionality through conservative measures.

\section{ACKNOWLEDGEMENTS:}

We would like to thank the Rowan Department of Family Medicine for supporting this research project. Rowan University's Institutional Review Board approved this study.

\section{AUTHOR DISCLOSURES:}

No relevant financial affiliations or conflicts of interest.

\section{REFERENCES:}

1. Fry LJ. Preliminary findings on the use of osteopathic manipulative treatment by osteopathic physicians. The Journal of the American Osteopathic Association. 1996;96(2):91. doi:10.7556/jaoa.1996.96.2.91.

2. Spaeth DG, Pheley AM. Use of Osteopathic Manipulative Treatment by Ohio Osteopathic Physicians in Various Specialties. The Journal of the American Osteopathic Association. 2003;103(1):16-26.

3. Johnson SM, Kurtz ME. Diminished Use of Osteopathic Manipulative Treatment and Its Impact on the Uniqueness of the Osteopathic Profession. Academic Medicine. 2001;76(8):821-828. doi:10.1097/00001888-200108000-00016.

4. Allee BA, Pollak MH, Malnar KF. Survey of Osteopathic and Allopathic Residents' Attitudes Toward Osteopathic Manipulative Treatment. The Journal of the American Osteopathic Association. 2005;105(12):551-561.

5. Johnson SM, Kurtz ME. Osteopathic Manipulative Treatment Techniques Preferred by Contemporary Osteopathic Physicians. The Journal of the American Osteopathic Association. 2003;103(5):219-224.

6. Johnson SM, Kurtz ME, Kurtz JC. Variables influencing the use of osteopathic manipulative treatment in family practice. The Journal of the American Osteopathic Association. 1997;97(2):80. doi:10.7556/ jaoa.1997.97.2.80
7. Noll DR, Degenhardt BF, Morley TF, et al. Efficacy of osteopathic manipulation as an adjunctive treatment for hospitalized patients with pneumonia: a randomized controlled trial. Osteopathic Medicine and Primary Care. 2010;4(1):2. doi:10.1186/1750-4732-4-2.

8. Licciardone JC, Gatchel RJ, Aryal S. Recovery From Chronic Low Back Pain After Osteopathic Manipulative Treatment: A Randomized Controlled Trial. The Journal of the American Osteopathic Association. 2016;116(3):144. doi:10.7556/jaoa.2016.031.

9. Channell MK, Wang Y, Mclaughlin MH, Ciesielski J, Pomerantz SC. Osteopathic Manipulative Treatment for Older Patients: A National Survey of Osteopathic Physicians. The Journal of the American Osteopathic Association. 2016;116(3):136. doi:10.7556/jaoa.2016.030.

10. Smith, Michael S, Olivas, Jairo, and Smith, Kristy. "Manipulative Therapies: What Works." American Family Physician, vol. 99, no. 4, Feb. 2019.

11. Bener A, Dafeeah EE, Alnaqbi K, et al. An Epidemiologic Analysis of Low Back Pain in Primary Care. Journal of Primary Care \& Community Health. 2013;4(3):220-227. doi:10.1177/2150131913479385.

12. Vos T, et al. Years lived with disability (YLDs) for 1160 sequelae of 289 diseases and injuries 1990-2010: a systematic analysis for the Global Burden of Disease Study 2010. Lancet. 2012;380(9859):2163-2196.

13. Qaseem A, Wilt TJ, McLean RM, Forciea MA, for the Clinical Guidelines Committee of the American College of Physicians. Noninvasive Treatments for Acute, Subacute, and Chronic Low Back Pain: A Clinical Practice Guideline from the American College of Physicians. Ann Intern Med. [Epub ahead of print 14 February 2017]166:514-530. doi: 10.7326/ M16-2367.

14. Marshall B, Bland MK, Hulla R, Gatchel RJ. Considerations in addressing the opioid epidemic and chronic pain within the USA. Pain Management. 2019;9(2):131-131-138.

15. Dahlhamer J, Lucas J, Zelaya C, Nahin R, Mackey S, DeBar L, Kerns R, Von Korff M, Porter L, Helmick C. Prevalence of chronic pain and high impact chronic pain among adults - United States, 2016. MMWR. September 14, 2018.

16. Hedegaard H, Miniño AM, Warner M. Drug Overdose Deaths in the United States, 1999-2018.pdf icon NCHS Data Brief, no 356. Hyattsville, MD: National Center for Health Statistics. 2020.

17. Ackerman SL, Gonzales R, Stahl MS, Metlay JP. One size does not fit all: evaluating an intervention to reduce antibiotic prescribing for acute bronchitis. BMC Health Services Research. 2013;13(1). doi:10.1186/14726963-13-462.

18. Moerenhout T, Borgermans L, Schol S, Vansintejan J, Van De Vijver E, Devroey D. Patient health information materials in waiting rooms of family physicians: do patients care? Patient Preference and Adherence. 2013;7:489-497. doi:10.2147/ppa.s45777. 